\title{
Inguinodynia: review of predisposing factors and management
}

\section{Inguinodinia: revisão sobre fatores predisponentes e manejo}

Cirênio de Almeida Barbosa, tCbC-MG 1,2,3; Deborah Campos Oliveira id 4; Nathália Moura de-Melo-Delgado'; Júla Gallo deAlvarenga Mafra ${ }^{1}$; Ronald Soares dos Santos ${ }^{1}$; Weber Chaves Moreira, TCBC-MG ${ }^{2,3}$.

\section{A B S T R A C T}

\begin{abstract}
Herniorrhaphy is one of the most common surgical procedures, with an estimated 20 million operations performed annually worldwide. One of the common complications associated with this procedure is inguinodynia, defined as pain beyond three months after inguinal hernia surgery. In this review, we have addressed the main aspects of this complication with current articles, published in the last five years. Inguinodynia has a multifactorial nature and studies have shown that its development is related to the surgical technique and intrinsic factors of the patient that imply greater predisposition to this phenomenon. In this regard, it has been discussed which surgical techniques imply a lower incidence of this complication. Many studies have focused on understanding intrinsic features of each patient, both in physical and cognitive aspects, and how the approach of these factors can favor a better post-surgical recovery. The treatment of this condition is still challenging, and there are no established universal guidelines. We believe that due to its multifactorial nature, the treatment is hampered due to the individuality inguinodynia presentations.
\end{abstract}

Keywords: Chronic Pain. Inguinal Hernia. Herniorrhaphy.

\section{INTRODUCTION}

b nguinal hernia is a bulging of the abdominal wall, caused by the protrusion of the contents of the abdominal cavity to the subcutaneous space. The recommended treatment is herniorrhaphy. Currently, the Lichtenstein technique, the tension-free repair procedure, is the most recommended. In addition to this technique, laparoscopic repair has gained relevance because it causes less pain and requires less hospitalization time and postoperative recovery. Laparoscopic herniorrhaphy has two main approaches: total extraperitoneal (TEP) and preperitoneal transabdominal (TAPP) ${ }^{1-3}$.

The advent of these techniques has enabled a significant reduction in inguinal hernias' recurrence rates, one of the main postoperative complications. On the other hand, there has been a significant increase in the incidence of inguinodynia, currently the most frequent complication after herniorrhaphy ${ }^{4,5}$.

The International Association for the Study of Pain (IASP) defines Inguinodynia, also called chronic inguinal pain after herniorrhaphy, as pain lasting greater than three months after herniorrhaphy. The incidence of inguinodynia varies between $10 \%$ and $12 \%$ in the world and, although the pain intensity in most cases is mild, it can be severe and disabling, compromising quality of life $e^{6-9}$.

Annually, about 20 million operations for inguinal hernia repair are performed worldwide. This emphasizes the need to understand and identify the etiological factors involved and to define guidelines for the management of affected patients. Therefore, we propose a narrative review with current scientific evidence, to explore this theme further ${ }^{9-11}$.

\section{METHOD}

In this study, we adopted the literature review as a methodological strategy. We performed a search for articles in the Latin American and Caribbean Health Sciences (LILACS), Scientific Electronic Library Online (SciELO), and National Library of Medicine (PubMed)

1 - Universidade Federal de Ouro Preto, Departamento de Cirurgia, Ginecologia e Obstetrícia e Propedêutica da Escola de Medicina - Ouro Preto - MG - Brasil 2 - Colégio Brasileiro de Cirurgia, Titular - Belo Horizonte - MG - Brasil 3 - Colégio Brasileiro de Cirurgia e do Aparelho Digestivo, Titular - Bela Vista - SP - Brasil 4 - Universidade Federal de Ouro Preto, Departamento de Biotecnologia - Ouro Preto - MG - Brasil 
databases, using the term inguinodynia and its synonym, chronic inguinal pain after herniorrhaphy, in Portuguese and in English.

Original studies (case reports, clinical trials, and observational studies), published between 2015 and 2020, in English and in Portuguese were eligible. We did not include non-systematic reviews, book chapters, and conference proceedings.

We initially selected the articles by title and abstract, and then proceeded with critical reading and synthesis. The search resulted in 154 articles, of which we included 24 for this work. The flowchart in Figure 1 shows the study selection process, as well as the reasons for exclusions.

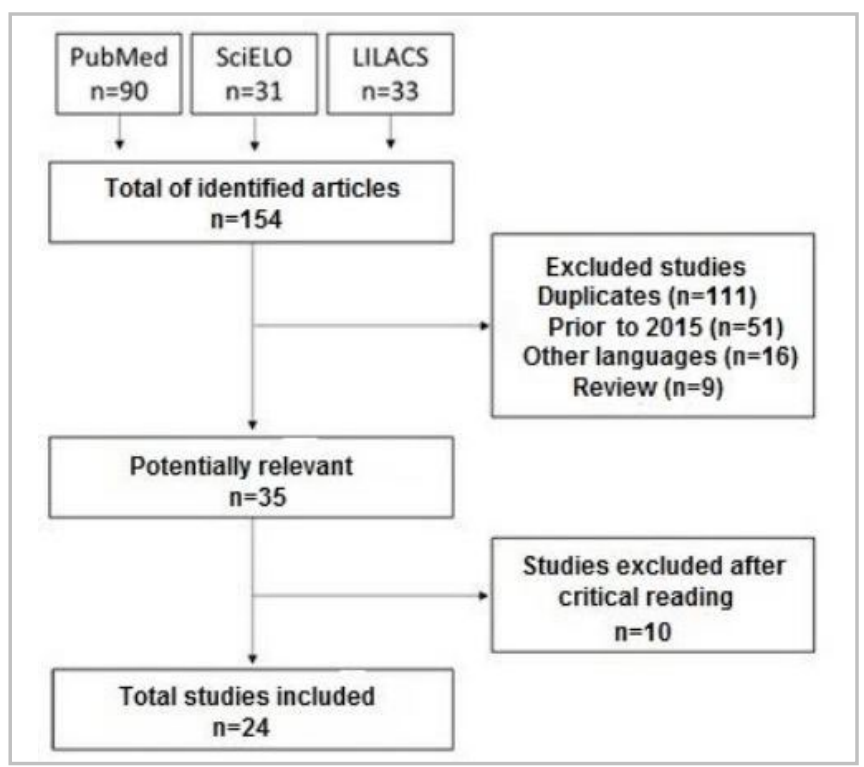

Figure 1. Procedures for searching and selecting articles.

\section{RESULTS AND DISCUSSION}

\section{Etiology}

Inguinodynia is multifactorial and can be caused by damage to one or more nerves in the region (ileohypogastric, ileoinguinal, and genitofemoral nerves), causing neuropathic pain, or inflammatory processes related to the use of mesh or other factors, resulting in nociceptive pain ${ }^{4}$.

Neuropathic pain results from direct nerve damage during the operation and may consist of sectioning, stretching, trapping, crushing, or compression by the suture, mesh, staples, or other fixation devices. Neuropathic pain is characterized by paresthesia, hypoesthesia, allodynia and hyperalgesia, symptoms that worsen during walking and sitting movements ${ }^{5,10,11}$.

When injured, the interrupted axons try to regenerate to restore innervation. However, some become atrophic, and others form a neuroma, a scar tissue. These last two events are implicated in the etiology of neuropathic pain ${ }^{9,11}$.

In nociceptive pain, on the other hand, the damage affects the tissue adjacent to the nervous structures and is due to the inflammatory reaction and muscle and tendon injuries. This type of pain is commonly reported as continuous and inaccurate, with little intensity. It is also characterized as localized, diffuse, or projected pain in the surrounding areas, and can occur weeks or months after surgery ${ }^{5,10,12}$.

Polypropylene, a synthetic material of meshes usually used in tension-free techniques, can trigger granulomatous reactions around the individual fibers of the material, which unite and encapsulate the mesh, producing a rigid scar with little elasticity, which it is related to pain ${ }^{1,13}$

There are also cases in which these symptoms affect the penis and testicles beyond the inguinal region, causing pain before, during, and after ejaculation. Though often ignored, this symptom is common in one third of men with chronic post-herniorrhaphy pain. The migration of the mesh has been associated with the appearance of these symptoms in this group ${ }^{9,14}$.

The differentiation of chronic inguinal pain into nociceptive and neuropathic pain has little clinical significance, since there are no diagnostic methods that make it possible to distinguish the pain. In addition, symptoms, presentations, and findings overlap, which also hampers clinical differentiation ${ }^{5}$.

No study has investigated whether the two types of pain can be safely distinguished. Some authors, however, describe nociceptive pain as acute, tending to decrease over time, while neuropathic pain can persist for long periods 8,15

\section{Risk factors}

The identification of risk factors is of great 
importance for an individualized and stratified approach. In a systematic review, Reinpold $(2017)^{5}$ observed that the risk factors with a strong level of evidence are female sex, younger age (below 40 and 50 years), intense preoperative and early postoperative inguinal pain, and recurrent inguinal hernia.

Data from the literature also point to other clinical conditions, surgical technique, choice of mesh, and neurocognitive and emotional factors as relevant to the occurrence of chronic pain ${ }^{6}$. Reinpold $(2017)^{5}$ cites genetic factors that predispose to inguinodynia, inappropriate use of sutures and staples, and other postoperative complications. However, according to the author, these factors have low to moderate levels of evidence.

Concerning the surgical technique employed, inguinodynia has been more frequent in individuals undergoing open surgery compared with the laparoscopic approach ${ }^{5,11,12}$. Urkan and Peker (2019)12 compared the incidence of inguinodynia in individuals undergoing TEP and the Lichtenstein technique, and found a lower incidence in the former. In TEP, no repair is applied through muscles and tendons, and there is less chance of dissection of regional sensory nerves. These factors justify the lower incidence in the group submitted to this technique.

The choice of mesh and type of fixation are also factors that contribute to the development of chronic pain ${ }^{1,13}$. As for fixation, the use of staples has been widely debated in recent years, since they can induce damage to sensitive nerves and lead to neuropathy. In the case of TEP, studies show no clinical advantages with fixing the mesh, and it can be dispensed in up to $95 \%$ of cases, being recommended for exceptional cases ${ }^{16,17}$.

Some factors have been studied regarding the predictive potential of chronic pain. Reinpold (2017) cites the presence of paresthesia in the surgical area after the procedure, the absence of visible bulging in the preoperative period, and longer recovery time as factors capable of predicting this outcome.

In addition, some studies show that factors related to the patient, such as advanced age, history of previous repair, smoking, glycemic control, and other postoperative comorbidities and complications are independent predictors of inguinodynia ${ }^{6,18}$.

\section{Management}

There are no universally accepted guidelines for the management of patients with inguinodynia. Correct diagnosis is essential, ruling out other causes of pain and recurrence. Currently, watchful waiting, associated or not with analgesia, can be considered the first line of treatment, which results in pain improvement in most cases. Injections with local anesthetics can be used to relieve pain, although they are more used during diagnosis, in identifying which nerve is injured7,10,11.

The persistence of pain after a few months warrants systemic pharmacological interventions. Among the drugs commonly used, there are non-steroidal anti-inflammatory drugs, tricyclic antidepressants, and serotonin reuptake inhibitors. For these cases, treatment is more challenging, requiring multi-professional approaches and even surgery to remove the mesh or neurectomy $y^{7,11,19}$.

In many cases, the removal of the mesh is sufficient to reverse the chronic pain. However, during the procedure, damage to nerve structures may occur that is not visible to the surgeon, causing pain to persist. Thus, the recommendation is removal of the mesh followed by neurectomy ${ }^{10}$.

Selective or triple neurectomy has a high success rate. The neurological deficit is negligible, comprising the impairment of the cremasteric reflex and anesthesia of the area of the inguinoscrotal fold, with about 3 to 5 $\mathrm{cm}$ in diameter. It is important to note that, in women, the genital branch of the genitofemoral nerve must be preserved, as it is the sensory nerve for the labia majora. In addition, as with other more conservative treatments, there is the possibility of side effects after neurectomy and there is also a risk that the treatment may not be effective, or even worsen the pain, although it is a rare event. This technique can be ineffective especially due to scarring and neuropathy near the inguinal canal 10,20,21.

Triple neurectomy is the safest option and has been recommended the most, but it is a more aggressive technique that affects a larger region. Thus, current trends encourage selective neurectomy. Regarding the approach, open neurectomy is still considered the best choice. Laparoscopic neurectomy is also effective, but the disadvantage is the need for adequate team training ${ }^{22}$. 
Verhagen et al. (2018) ${ }^{23}$ compared the efficacy of neurectomy with combined injection of lidocaine, corticosteroids, and hyaluronic acid for the treatment of inguinodynia. Neurectomy was three times more effective than injection and less than a third of patients benefited from the injection technique.

Landry et al. $(2019)^{6}$ describe the use of cognitive behavioral therapy (CBT) to improve pain symptoms. The authors report improvement in all patients, observing total or almost total improvement in most. CBT in such cases is part of a multi-professional program that combines the use of anesthetic blockades with CBT in pre-rehabilitation and recovery.

In short, there is no standardized technique for management, because the etiology of inguinodynia is multifactorial and each patient's condition presents in a unique way, which requires an individualized approach. Therefore, the systematization of inguinodynia management depends on additional studies, evaluating each treatment modality, to minimize the symptoms of this complication ${ }^{20}$.

\section{Prevention}

In recent years, scientific evidence has changed the treatment focus to prevent inguinodynia, whose onset is influenced by a multiplicity of factors, from those related to the technique to those related to the patient, such as life habits and the presence of other comorbidities $^{6}$.

According to Andercou et al. (2019) ${ }^{11}$, it is important to define a technique that avoids nerve damage. Studies show that inguinodynia is more frequent in patients undergoing open surgery, but it has also been shown that the incidence has decreased after surgeons become familiar with the anatomy of the region, since it is a complex and poorly understood region.

Studies show that nerve injuries are due to failure to visualize and protect nerves, failure to recognize the location of nerves' anatomical variations, and inadequate dissections. The identification of the three inguinal nerves reduces the risk of inguinodynia. However, few surgeons follow this recommendation ${ }^{15}$. Konschake et al. (2019) ${ }^{15}$ recommend performing an inguinal ultrasound to identify the nerves or visually identify them during open herniorrhaphy.

Prophylactic neurectomy has been an alternative to prevent the development of inguinodynia. Some studies show a lower incidence of inguinodynia in individuals undergoing this procedure. However, Urkan and Peker $(2019)^{12}$ point out that there is no high-quality evidence to justify its routine adoption.

Chinchilla-Hermida et al. (2017) ${ }^{24}$ and Zwaans et al. (2015)25 demonstrated that general anesthesia is a risk factor for the development of inguinodynia. A possible explanation would be that general anesthesia does not promote as powerful a central impulse block as spinal anesthesia. Spinal anesthesia has been shown to be a protective factor for the development of chronic pain in patients undergoing other surgical procedures, such as hysterectomies or cesarean sections. However, it is important to note the possibility of bias, since general anesthesia can be chosen for cases of larger hernias, uncooperative patients, or those who have greater risk factors for the development of chronic pain. On the other hand, some evidence suggests that the use of local anesthetics, both for infiltration in the surgical wound and for ilioinguinal/ iliohypogastric blockade, would be a more relevant strategy for the prevention of inguinodynia than the choice between general and spinal anesthesia24,25.

In the same study by Chinchilla-Hermida et al. $(2017)^{24}$, the use of non-steroidal anti-inflammatory drugs, such as diclofenac, in the first weeks after surgery performed under local anesthesia, helped to prevent the development of inguinodynia.

Crompton et al. ${ }^{26}$ demonstrated that blocking the iliohypogastric/ilioinguinal nerves with bupivacaine before surgery decreased the postoperative pain score, the need for opioid medications, the recovery time, and the reduction of pain in the long term.

Macroporous polypropylene meshes are preferred over other prosthetic materials. These products have large pores (>75 micrometers), allowing the material to be permeated by fibroblasts, collagen fibers, new blood vessels, and macrophages, essential factors for creating consolidated repair. Microporous materials, with pores $<10$ micrometers, do not promote sufficient inflammatory response nor provide sufficient 
tissue incorporation. Light monofilament materials are generally preferable, as they are flexible and more easily sterilized in cases involving postoperative infections. Light meshes can also have some advantages regarding longterm discomfort and foreign body sensation.

Flat, monofilament polymer meshes, with weight between 30 and $140 \mathrm{~g} / \mathrm{m}^{2}$ and with pores greater than $1 \mathrm{~mm}$, are recommended. There is evidence that meshes manufactured with monofilament threads display a lower risk of mesh-related complications. In summary, it appears that meshes with large pores (greater than or equal to $1 \mathrm{~mm}$ ) have superior biological behavior, with less likelihood of complications. These characteristics may have repercussions on the results regarding acute and chronic pain, the sensation of foreign body, resistance to infection, and contracture of the scar tissue, with a consequent decrease in the size of the implant, which can vary greatly depending on each mesh and on the interaction with the patient's tissues.

Several systematic reviews and meta-analyzes compared heavy versus light meshes ${ }^{27-28}$. The risk of chronic pain was significantly lower for the macroporous mesh. The magnitude of the risk reduction was similar in each of the meta-analyzes (for example, odds ratio [OR] $0.61,95 \% \mathrm{Cl} 0.50-0.74)^{28}$. Patients reported significantly less foreign body sensation with the light mesh, regardless of whether it was partially absorbable or non-absorbable.

In addition to factors related to the technique, other characteristics associated with the patient have been considered important determinants of inguinodynia, such as lifestyle and/or the presence of other comorbidities. Optimization of nutritional status, exercise, and smoking cessation have proven to be interventions capable of improving results 6 .

The psychological status of patients in the preoperative period is a factor related to the patient's evolution in the postoperative period. Anxiety and frustration have been associated with slower recovery and a higher risk of complications, while a state of optimism and positive expectations are related to a more favorable recovery ${ }^{6}$.

Landry et al. $(2019)^{6}$ demonstrated positive results by applying cognitive behavioral therapy, showing that emotional well-being could prevent chronic inguinal pain after herniorrhaphy.

Finally, Chinchilla-Hermida et al. (2017) $)^{24}$ report the lack of a culture of prevention of this condition among professionals, as well as the absence of data that could help determine the size of the problem.

\section{CONCLUSION}

There are still many questions about the etiology of inguinodynia, the risk factors involved, and the ways of handling and preventing this complication. The results show that although the surgical technique used influences considerably the occurrence of chronic pain, factors related to the cognitive and emotional aspects, as well as the patient's lifestyle, all play a role.

Our review showed that, despite scientific evidence, there are no established guidelines for the prevention and management of inguinodynia. Furthermore, as it is a multifactorial disorder, there is a tendency towards a more individualized approach.

\section{R E S U M O}

A herniorrafia é um dos procedimentos cirúrgicos mais realizados, com estimativa de 20 milhões de operações feitas anualmente em todo o mundo. Uma das complicações comuns associadas a esse procedimento é a inguinodinia, definida como dor inguinal crônica, com duração superior a três meses após herniorrafia inguinal. Nesta revisão, abordamos os principais aspectos dessa complicação com base em artigos sobre o tema, publicados nos últimos cinco anos. A inguinodinia tem natureza multifatorial e estudos mostram que está relacionada à técnica cirúrgica e aos fatores intrínsecos do paciente, que implicam maior predisposição a esse fenômeno. Nesse sentido, têm sido discutidas quais técnicas cirúrgicas implicam menor incidência dessa complicação. Muitos estudos têm se concentrado em compreender características inerentes a cada paciente, tanto no aspecto físico, quanto cognitivo, e como a abordagem desses fatores pode favorecer a melhor recuperação pós-cirúrgica. O tratamento dessa condição ainda é desafiador e não há diretrizes universais estabelecidas. Acreditamos que, devido à natureza multifatorial, o tratamento é dificultado em razão da individualidade das apresentações da inguinodinia.

Palavras chave: Dor Crônica. Hérnia Inguinal. Herniorrafia. 


\section{REFERENCES}

1. Kalra T, Soni RK, Sinha A. Comparing Early Outcomes using Non Absorbable Polypropylene Mesh and Partially Absorbable Composite Mesh through Laparoscopic Transabdominal Preperitoneal Repair of Inguinal Hernia. J Clin Diagn Res. 2017;11(8):PC13PC16.

2. Cunha e Silva JA, Oliveira FMM, Ayres AFSMC, Iglesias ACRG. Herniorrafia inguinal convencional com tela autofixante versus videolaparoscópica totalmente extraperitoneal com tela de polipropileno: resultados no pós-operatório precoce. Rev Col Bras Cir. 2017;44(3):238-44.

3. Teixeira FMC, Pires FPAA, Lima JSF, Pereira FLC, Silva CA, de Paula MHS, et al. Estudo de revisão da cirurgia de hernioplastia inguinal: técnica de Lichtenstein versus laparoscópica. Rev Méd Minas Gerais. 2017;27(1-8):44-51.

4. Dias BG, Santos MP, Chaves ABJ, Willis M, Gomes $M C$, Andrade $F T$, et al. Inguinodynia in patients submitted to conventional inguinal hernioplasty. Rev Col Bras Cir. 2017;44(2):112-5.

5. Reinpold W. Risk factors of chronic pain after inguinal hernia repair: a systematic review. Innov Surg Sci. 2017;2(2):61-8.

6. Landry M, Lewis R, Lew M, Forman B, Heidel E, Ramshaw B. Evaluating effectiveness of cognitive behavioral therapy within multimodal treatment for chronic groin pain after inguinal hernia repair. Surg Endosc. 2020;34(7):3145-52. Epub 2019 Aug 28.

7. Narita M, Jikihara S, Hata $H$, Matsusue $R$, Yamaguchi $T$, Otani $T$, et al. Surgical experience of laparoscopic retroperitoneal triple neurectomy for a patient with chronic neuropathic inguinodynia. Int J Surg Case Rep. 2017;40:80-4.

8. Claus CMP, Oliveira FMM, Furtado ML, Azevedo MA, Roll S, Soares $G$, et al. Orientações da Sociedade Brasileira de Hérnia (SBH) para o manejo das hérnias inguinocrurais em adultos. Rev Col Bras Cir. 2019;46(4):e20192226.

9. lakovlev V, Koch A, Petersen K, Morrison J, Grischkan $D$, Oprea $V$, et al. A pathology of mesh and time: dysejaculation, sexual pain, and orchialgia resulting from polypropylene mesh erosion into the spermatic cord. Ann Surg. 2018;267(3):569-75.

10. Fafaj A, Tastaldi L, Alkhatib H, Zolin S, Alaedeen $D$, Petro $C$, et al. Surgical treatment for chronic postoperative inguinal pain-short term outcomes of a specialized center. Am J Surg. 2020;219(3):425-8.

11. Andercou O, Olteanu G, Stancu B, Mihaileanu F, Chiorescu S, Dorin M. Risk factors for and prevention of chronic pain and sensory disorders following inguinal hernia repair. Annali italiani di chirurgia. 2019;90:442-6.

12. Urkan M, Peker YS. TEP versus Lichtenstein, which one to choose? A retrospective cohort study. Rev Assoc Med Bras. 2019;65(9):1201-7.

13. Heymann F, von Trotha KT, Preisinger C, LynenJansen $\mathrm{P}$, Roeth AA, Geiger $\mathrm{M}$, et al. Polypropylene mesh implantation for hernia repair causes myeloid cell-driven persistent inflammation. JCl Insight. 2019;4(2):e123862.

14. Verhagen T, Loos MJA, Scheltinga MRM, Roumen $\mathrm{RMH}$. Surgery for chronic inguinodynia following routine herniorrhaphy: beneficial effects on dysejaculation. Hernia. 2016;20(1):63-8.

15. Konschake $M$, Zwierzina $M$, Moriggl $B$, Függer $R$, Mayer $F$, Brunner $W$, et al. The inguinal region revisited: the surgical point of view : An anatomicalsurgical mapping and sonographic approach regarding postoperative chronic groin pain following open hernia repair. Hernia. 2020;24(4):883-94. Epub 2019 Nov 27.

16. Meyer A, Dulucq JI, Mahajna A. Correção de hérnia laparoscópica: tela sem fixação é viável? ABCD Arq Bras Cir Dig. 2013;26(1):27-30.

17. Ramshaw $B$, Vetrano $V$, Jagadish $M$, Forman $B$, Heidel E, Mancini M. Laparoscopic approach for the treatment of chronic groin pain after inguinal hernia repair. Surgical Endosc. 2017;31(12):5267-74.

18. Huerta S, Patel PM, Mokdad AA, Chang J. Predictors of inguinodynia, recurrence, and metachronous hernias after inguinal herniorrhaphy in veteran patients. Am J Surg. 2016;212(3):391-8.

19. Andresen K, Rosenberg J. Management of chronic pain after hernia repair. J Pain Res. 2018;11:675-81.

20. Moore AM, Bjurstrom MF, Hiatt JR, Amid PK, Chen DC. Efficacy of retroperitoneal triple neurectomy for refractory neuropathic inguinodynia. Am J Surg. 
2016;212(6):1126-32.

21. Bjurström MF, Nicol AL, Amid PK, Lee CH, Ferrante FM, Chen DC. Neurophysiological and clinical effects of laparoscopic retroperitoneal triple neurectomy in patientswith refractory postherniorrhaphyneuropathic inguinodynia. Pain Practice. 2017;17(4):447-59.

22. Moreno-Egea A. Surgical management of postoperative chronic inguinodynia by laparoscopic transabdominal preperitoneal approach. Surg Endosc. 2016;30(12):5222-7.

23. Verhagen $T$, Loos MJ, Scheltinga MR, Roumen RM. The groinpain trial: a randomized controlled trial of injection therapy versus neurectomy for postherniorraphy inguinal neuralgia. Ann Surg. 2018;267(5):841-5.

24. Chinchilla-Hermida PA, Baquero-Zamarra DR, Guerrero-Nope C, Bayter-Mendoza EF. Incidence of chronic post-surgical pain and its associated factors in

Received in: 07/05/2020

Accepted for publication: 18/09/2020

Conflict of interest: no.

Funding source: none. patients taken to inguinal hernia repair. Rev Colomb Anestesiol. 2017;45(4):291-9.

25. Zwaans WA, Verhagen T, Roumen RM, Scheltinga MR. Factors determining outcome after surgery for chronic groin pain following a Lichtenstein hernia repair. World J Surg. 2015;39(11):2652-62.

26. Crompton JG, Dawes AJ, Donald GW, Livhits MJ, Chandler CF. Perineural bupivacaine injection reduces inguinodynia after inguinal hernia repair. Surgery. 2016;160(6):1528-32.

27. Zhong C, Wu B, Yang Z, Deng X, Kang J, Guo B, et al. A meta-analysis comparing lightweight meshes with heavyweight meshes in Lichtenstein inguinal hernia repair Surg Innov. 2013;20(1):24-31.

28. Sajid MS, Leaver C, Baig MK, Sains P. Systematic review and meta-analysis of the use of lightweight versus heavyweight mesh in open inguinal hernia repair. Br J Surg. 2012;99(1):29-37.

\section{Mailing address:}

Cirênio de Almeida Barbosa

E-mail: cireniobarbosa@gmail.com

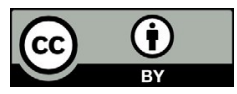

